\title{
Variation in mate preference across a house mouse hybrid zone
}

\author{
G Ganem ${ }^{1}, \mathrm{C} \mathrm{Litel}^{2}$ and T Lenormand ${ }^{3}$ \\ ${ }^{1}$ Laboratoire Génétique et Environnement, Institut des Sciences de l'Evolution de Montpellier UMR 5554 (UM2, CNRS), Université \\ Montpellier II, CC 065, Montpellier, France; ${ }^{2}$ Laboratoire Génome Populations Interactions Adaptation, UMR 5171, Université \\ Montpellier II, Montpellier, France and ${ }^{3}$ Centre d'Ecologie Fonctionelle et Evolutive, UMR 5175, Montpellier, France
}

\begin{abstract}
Reproductive character displacement is known to occur at the borders of a secondary contact zone between the two European subspecies of the house mouse (in Jutland, Denmark), where selection against hybridization occurs. This study assessed patterns of mate preference in naturally occurring hybrids of the two subspecies. Mate odour choice was investigated in male and female mice sampled across the hybrid zone. Odour samples comprised urine (from the opposite sex to the test animal) obtained from populations geographically distant from the hybrid zone. Urine is known to carry subspecies recognition signals. The behavioural results changed across the hybrid zone, and were analysed by a model of clinal variation. This behavioural cline was compared with the allozyme cline across the same hybrid
\end{abstract}

Keywords: mate choice; urine; allopatric signals; hybrid zone; clinal analysis; Denmark

zone. Males on both sides of the hybrid zone showed an assortative preference, which shifted significantly and abruptly $\sim 10 \mathrm{~km}$ from the genetic centre of the hybrid zone on the Mus musculus musculus side. Directional preference was not detected in females, which could relate to variation in sexual receptivity. Our model indicates that the peculiar pattern of male preference could involve several genes and be characterized by mild to strong epistasis favouring the expression of $M$. m. domesticus-like preference over a large portion of the hybrid zone. This study may provide the first picture of the genetic determination of mate preference in a mammal.

Heredity (2008) 100, 594-601; doi:10.1038/hdy.2008.20; published online 16 April 2008

\section{Introduction}

Members of a species share the same mate recognition system (Paterson, 1985; Littlejohn, 1993; Ryan and Rand, 1993; Lambert and Spencer, 1995), a characteristic that is expected to restrict hybridization. Nonetheless, mixed breeding occurs when the mate recognition system is not specific enough (Rhymer and Simberloff, 1996; Bronson et al., 2003; Rosenfield and Kodric-Brown, 2003).

Hybrids have been found to have mating signals with intermediate characteristics, or to exhibit novel elements (Wells and Henry, 1998; Vedenina and Helversen, 2003), as well as to express preferences different from the parental forms (Wells and Henry, 1998). How hybridization affects the mate recognition system is an important question, which could provide an insight into the characteristics and the mode of inheritance of mate recognition systems (Hatfield, 1997). Natural hybrid zones are ideal geographical settings to compare the recognition system of parental forms and their hybrids. This applies particularly to unimodal hybrid zones, which are made of a continuum of hybrid populations

Correspondence: Dr G Ganem, Laboratoire Génétique et Environnement, Institut des Sciences de l'Evolution, Université Montpellier II, CC 065, 34095 Montpellier cedex 5, France.

E-mail: guila.ganem@univ-montp2.fr

Received 23 July 2007; revised 14 November 2007; accepted 10

March 2008; published online 16 April 2008 resulting from multiple crossing and back-crossing of hybrids.

The aim of this study was to assess the influence of hybridization on patterns of preference for parental type odorant mate signals across a unimodal hybrid zone between the two European subspecies of the house mouse, Mus musculus musculus and M. m. domesticus. The two house mouse subspecies interbreed in zones of secondary contact that form a long and narrow hybrid zone running from Denmark to the Black sea (Boursot et al., 1993; Orth et al., 1996; Payseur et al., 2004; Macholán et al., 2007). Our study concerns the northernmost part of the house mouse hybrid zone, namely, central Jutland in Denmark (Raufaste et al., 2005). The Danish hybrid zone is one of the most extensively studied in the house mouse (Britton-Davidian et al., 2005; Dod et al., 2005; Raufaste et al., 2005 and references therein). Recently, an analysis of the patterns of allele frequency change at eight diagnostic autosomal allozyme loci across the Danish hybrid zone (Raufaste et al., 2005) confirmed that the hybrid zone conformed to the tension model, that is, a zone maintained by the balance between migration of parental forms into the hybrid zone and selection against hybridization (Barton and Hewitt, 1985). Raufaste et al. located the centre of this zone and calculated the intensity of the barrier to gene flow (of the order of $20 \mathrm{~km}$ on each side). Moreover, there is indirect evidence for reduced fitness of hybrids from data on variation of parasite loads across the zone (Moulia et al., 1991) and 
from data on reduced testis size, very high sterility rates of males and substantial reduction of fertility of females in F1 crosses between Danish strains (Britton-Davidian et al., 2005). Finally, the transition from the $M . m$. domesticus to the M.m. musculus variant of chromosome $\mathrm{Y}$ is very steep and occurs at the centre of the hybrid zone, indicating that this chromosome could be under strong selection in the hybrid genome (Dod et al., 2005).

Behavioural investigations involving the two subspecies from the borders of the zone have revealed assortative preference in males and females based on signals present in the mouse urine (Smadja and Ganem, 2002; Smadja et al., 2004). Moreover, the outcome of preference trials was consistent with direct observations of sexual interactions between the mice (Smadja and Ganem, 2002). Preference was found to be more marked in M. m. musculus than in M.m. domesticus, and in contact zone populations than in allopatric populations, suggesting an asymmetrical pattern of reproductive character displacement (Smadja and Ganem, 2005).

The present study addressed preference in hybrid mice for odorant stimuli sampled in populations that were geographically distant from the hybrid zone. Our aim was to obtain geographically neutral signals. In doing so, we were aware that the signals that we presented to the mice were unfamiliar, which therefore excludes any mechanism of preference based on 'recognition by association' or familiarity (Tang-Martinez, 2001). If preference occurred, we expected it to be because of 'phenotype matching', that is, the mouse compares the stimuli to a complex template built during ontogeny sensu lato, or due to a 'self-referencing' mechanism (Hauber and Sherman, 2001). Recent studies strongly suggest that assessment of odour similarity and genetic relatedness in the house mouse may involve a comparison with its own odour characteristics (Heth et al., 2003; Todrank et al., 2005).

We know that odour cues of populations of the two subspecies both in the border of the hybrid zone and in allopatry diverge, although to a lesser extent in the latter (Smadja and Ganem, 2008). If allopatric signals are different enough to be discriminated by mice from the hybrid zone, we expected both the recognition mechanisms mentioned above to lead to assortative preference in mice from the borders of the hybrid zone. However, a more variable pattern was expected among populations in the centre of the zone because of their variable genetic background and their heterogeneous social environment (that is, a given individual interacts with more than one genetic type in its social environment). Furthermore, preference of hybrids could not be predicted as it is also expected to depend on the genetics underlying the preference traits (for example, dominance).

This study reports results based on measures of preference for opposite sex odour stimuli in wild mice sampled across the hybrid zone. We constructed the best fit describing the geographical variation in the behavioural trait (with location being described by the geographical coordinates of the mice trapping sites in the hybrid zone). We estimated the shape and location of the preference cline and compared its characteristics with those of the allozyme cline analysed by Raufaste et al. (2005). Our analysis provides indirect information on the possible genetics underlying mate odour preference.

\section{Materials and methods}

\section{Mice and the study area}

Mice were trapped in farm buildings along a north-south transect across the hybrid zone of central Jutland in Denmark, and were obtained from 46 different locations. Social structure of populations of mice found in commensal habitats is typically hierarchical with social groups made up of a dominant male, several females and a small number of related sub-adult and juveniles (Van Zegeren, 1980). Both males and females mark the group territory with their urine (Hurst, 1990a, b).

Only mice trapped as adults were used in the behavioural tests (to ensure that their social ontogeny had taken place in natural conditions). Most trapping occurred in October and November 1998. Several additional farms at the borders of the hybrid zone were sampled in June 2000. The presence of pregnant and juveniles indicated that reproduction was taking place during the two trapping sessions.

The names of the trapping sites and their geographical coordinates are given in Table 1. Raufaste et al. (2005) calculated coordinates for each locality by projecting their geographical coordinates onto a line, which followed the direction of maximum gradient changes of allele frequency for eight diagnostic autosomal loci across the hybrid zone. We used the calculations of these authors as well as their estimates for the position of the centre of the zone to assign each trapping site to a distance from that centre. Mice trapped in sites with projected coordinates north of the centre were considered to carry M. m. musculus-like genomes (and to be on the musculus side), and those located south of the centre were considered to carry $M . m$. domesticus-like genomes (and to be on the domesticus side). This classification is consistent with both the allozymes and the Y-chromosome clines (Dod et al., 2005). Following this criterion, our study sample consisted of 64 mice of the $M . m$. domesticus type and 153 mice of the M. m. musculus type. The larger number of mice of the musculus type is due to the asymmetrical shape of the Danish hybrid zone: larger on musculus than on domesticus side (Raufaste et al., 2005). The average hybrid index (HI, \% of M. m. musculus alleles) for the eight diagnostic alleles (Amy, Es1, Es10, Es2, Gpd, Mpi, Np and Pgm) involved in the Raufaste et al. study was obtained for each of our trapping sites from the authors (Table 1).

\section{Experimental procedure: the urinary stimuli}

Urine was collected from strains derived from wild-caught mice sampled in locations distant from the areas where the two subspecies are in contact, and maintained in standardized laboratory conditions. The breeding procedure had been designed to avoid strong inbreeding. The strains were as follows: M. m. musculus: 'MH'-Hungary (11 generations of breeding) and 'MPB'-Poland (11 generation of breeding); $M$. $m$. domesticus: 'BIK'-Israel (34 generations of breeding) and 'BZO'-Algeria (28 generations of breeding). They were obtained (except for $\mathrm{MH}$ ) from the genetic house mouse repository (http://www.univ-montp2.fr/ $\sim$ genetix/souris.htm). Mice were housed in pairs and were fed the same laboratory standard pellet. Samples of urine were collected by a gentle pressure on the mouse 
Table 1 Details of the geographical coordinates of trapping localities, their distance (in km) from the centre of the hybrid zone, as well as the average frequency of M. $m$. musculus alleles (HI) for eight diagnostic alleles for each local population (distance from the centre is calculated from the transect coordinates in Raufaste et al. (2005))

\begin{tabular}{|c|c|c|c|c|c|c|c|}
\hline Subspecies side & Locality & Longitude & Latitude & $\begin{array}{c}\text { Distance from the centre of } \\
\text { the hybrid zone }(\mathrm{km})\end{array}$ & $H I$ & Preference $\mathrm{R}$ of males & Preference $\mathrm{R}$ of females \\
\hline domesticus & Kastvra A & 522.15 & 6129.2 & -44.0 & 0.007 & $-0.036 \pm 0.29(n=5)$ & $0.215 \pm 0.19(n=3)$ \\
\hline domesticus & Lauritzminde & 541.415 & 6144.14 & -29.2 & 0 & $-0.294 \pm 0.34(n=2)$ & \\
\hline domesticus & Baeklund & 516.2 & 6149.3 & -24.8 & 0.048 & $-0.341 \pm 0.47(n=6)$ & $0.062 \pm 0.32(n=12)$ \\
\hline domesticus & Vranderup & 524.8 & 6149.75 & -23.3 & 0.19 & & $-1.792(n=1)$ \\
\hline domesticus & Gesten & 511.2 & 6154.7 & -20.1 & 0.28 & $0.201(n=1)$ & $0.000(n=1)$ \\
\hline domesticus & Trelde & 549.1 & 6162.3 & -18.3 & 0.14 & & $0.847(n=1)$ \\
\hline domesticus & Vejlby & 545.4 & 6162.95 & -15 & 0.14 & $-0.182(n=1)$ & \\
\hline domesticus & Baekke & 509.7 & 6160.6 & -14.4 & 0.21 & $-0.707 \pm 0.61(n=5)$ & $0.280 \pm 0.28(n=2)$ \\
\hline domesticus & Viuf & 531.7 & 6158.85 & -13.5 & 0.14 & $0.087 \pm 0.21(n=3)$ & $-0.041 \pm 0.09(n=3)$ \\
\hline domesticus & Rands & 543.4 & 6164.75 & -12.3 & 0.23 & $-1.080(n=1)$ & $-0.421 \pm 0.18(n=3)$ \\
\hline domesticus & Starup & 487.1 & 6166.8 & -11 & 0.19 & $0.223(n=1)$ & \\
\hline domesticus & Hojenkirke & 531 & 6168.9 & -3.6 & 0.18 & $0.015 \pm 0.23(n=2)$ & $0.195 \pm 0.21(n=10)$ \\
\hline domesticus & Smakaer & 520.4 & 6171.2 & -2.6 & 0.34 & $-0.405(n=1)$ & \\
\hline musculus & Engelsholm mark & 521.1 & 6173.55 & -0.16 & 0.56 & $-0.998(n=1)$ & \\
\hline musculus & Braendgarde & 512.2 & 6176.7 & 1.9 & 0.67 & $-0.443 \pm 0.13(n=2)$ & $-0.071 \pm 0.76(n=2)$ \\
\hline musculus & Vester Hornstrup & 526.2 & 6175.9 & 2.8 & 0.47 & $-0.009 \pm 0.46(n=2)$ & $0.139 \pm 0.25(n=5)$ \\
\hline musculus & Gammelby & 520.75 & 6177.45 & 4.15 & 0.6 & & $1.743(n=1)$ \\
\hline musculus & Rugballe B & 528 & 6177.05 & 4.15 & 0.58 & $-0.934(n=1)$ & \\
\hline musculus & Hovertoft & 532.5 & 6176.5 & 4.2 & 0.75 & $0.773(n=1)$ & $0.266 \pm 0.35(n=5)$ \\
\hline musculus & Hover kirke A & 531 & 6176.7 & 4.2 & 0.63 & $-0.427(n=1)$ & \\
\hline musculus & Kiddelund & 522.9 & 6179.5 & 6.0 & 0.8 & $0.248 \pm 0.25(n=2)$ & $0.065(n=1)$ \\
\hline musculus & Hoegelund & 509.8 & 6182.1 & 6.95 & 0.67 & & $0.038 \pm 0.40(n=3)$ \\
\hline musculus & Hjortlund & 504.2 & 6182.8 & 6.96 & 0.64 & $-0.143(n=1)$ & \\
\hline musculus & Hygum A & 526 & 6181.6 & 8.43 & 0.91 & $-0.121 \pm 0.17(n=4)$ & $-0.097 \pm 0.55(n=4)$ \\
\hline musculus & Langelund-F & 504.25 & 6184.8 & 8.95 & 0.74 & $-1.100(n=1)$ & $-0.203 \pm 0.20(n=2)$ \\
\hline musculus & Riis A & 520.1 & 6185.5 & 11.6 & 0.69 & $0.567 \pm 0.82(n=2)$ & $-0.829 \pm 0.62(n=3)$ \\
\hline musculus & Givskud Z & 522 & 6185.4 & 12.25 & 0.8 & $0.495 \pm 0.27(n=6)$ & $0.055 \pm 0.29(n=7)$ \\
\hline musculus & Aadel A & 528.7 & 6185.4 & 12.5 & 0.71 & $-0.008 \pm 0.07(n=2)$ & $-0.650 \pm 0.36(n=2)$ \\
\hline musculus & Hvejsel & 526.45 & 6185.7 & 12.55 & 0.81 & $0.511(n=1)$ & $1.466(n=1)$ \\
\hline musculus & Riis & 519.9 & 6187.4 & 13.4 & 0.81 & $-0.560(n=1)$ & \\
\hline musculus & Vibjerg & 517.7 & 6188.1 & 13.9 & 0.88 & $0.636(n=1)$ & \\
\hline musculus & Hedegaard & 510.8 & 6189.2 & 14.1 & 0.88 & $0.000(n=1)$ & \\
\hline musculus & Aalsted Moelle & 529.2 & 6187.2 & 14.4 & 0.76 & $-0.466(n=1)$ & $0.203 \pm 0.20(n=2)$ \\
\hline musculus & Riis Mark & 521.3 & 6188.4 & 14.6 & 0.78 & $1.064 \pm 0.33(n=5)$ & $-0.065 \pm 0.07(n=5)$ \\
\hline musculus & Toerring Mark & 532.8 & 6192.2 & 19.8 & 0.812 & $0.720 \pm 0.82(n=3)$ & $-1.242 \pm 0.55(n=2)$ \\
\hline musculus & Thyregod & 520.4 & 6195 & 21.0 & 0.63 & $0.170 \pm 0.05(n=2)$ & \\
\hline musculus & Honum & 539.65 & 6193.5 & 22.25 & 0.81 & & $-0.126 \pm 0.67(n=5)$ \\
\hline musculus & Estrupholm & 518.4 & 6203.85 & 29.6 & 0.94 & $0.560(n=1)$ & $-1.84(n=1)$ \\
\hline musculus & Underup & 542.95 & 6200.6 & 30.0 & 0.87 & $0.154 \pm 0.29(n=8)$ & $-0.004 \pm 0.24(n=7)$ \\
\hline musculus & Traeden & 542 & 6202.65 & 31.7 & 0.8 & $-0.288(n=1)$ & \\
\hline musculus & Vestbirk & 545.5 & 6202.45 & 32.7 & 0.8 & $-0.557 \pm 0.09(n=3)$ & $0.162 \pm 0.29(n=7)$ \\
\hline musculus & Gosmer N & 574.65 & 6199.75 & 50.1 & 0.96 & $0.883 \pm 0.39(n=5)$ & $0.368 \pm 0.47(n=9)$ \\
\hline musculus & Spoettrup & 577.5 & 6199.2 & 52.2 & 0.93 & $0.168 \pm 0.17(n=2)$ & \\
\hline musculus & Elleskovhuse & 552.3 & 6223.2 & 54.5 & 0.95 & $0.887(n=1)$ & $-0.229 \pm 0.31(n=7)$ \\
\hline musculus & Abo & 564.5 & 6220.5 & 57.6 & 0.96 & $0.735 \pm 0.73(n=3)$ & $1.060 \pm 0.83(n=3)$ \\
\hline musculus & Borum Oestergaard & 563.9 & 6227.3 & 63.1 & 0.934 & $0.950 \pm 0.03(n=2)$ & $-0.294 \pm 0.40(n=2)$ \\
\hline
\end{tabular}

Localities were classified with reference to their position south (M. m. domesticus) or north (M. m. musculus side) of the centre of the hybrid zone. Number and gender (M/F) of mice involved in the behavioural test are provided. 
belly. They were collected from a minimum of five mice of a given sex and population. Four types of pools of urine were then constituted. For each sex and subspecies, urine from individuals from the two relevant populations was pooled and aliquots of each pool were kept at $-20^{\circ} \mathrm{C}$ before testing. Six pairs of pools were used in this study. Pooling was aimed to minimize the impact of between-individual heterogeneity of quality as well as that of between-population geographical variation and to maximize their shared genetic background (Penn and Potts, 1998). Testing was performed blind, that is, the observer did not know the identity of the pools.

\section{Experimental procedure: the testing apparatus}

The behavioural apparatus was made of transparent Plexiglas and plasticware. It consisted of a Y maze with a main branch that was $5 \mathrm{~cm}$ in diameter and $35 \mathrm{~cm}$ long. At one end was the start box ( 35 long $\times 23$ wide $\times 13 \mathrm{~cm}$ high) and at the other end were two $25 \mathrm{~cm}$ long secondary branches. The angle between the branches was $45^{\circ}$ (for additional details see Smadja and Ganem, 2002).

\section{Behavioural tests}

We measured a relative preference for a urinary stimulus by presenting a female or a male mouse with a two-way choice (Wagner, 1998). Based on considerations of the higher reproductive input of female (that is, pregnancy and lactation) than of male rodents, it is traditionally assumed that mate choice is mainly performed by females. Nevertheless, there is a growing evidence for the cost of breeding in males (Dewsbury, 1982: review studies involving several mammalian species; Drickamer et al. 2003; Gowaty et al., 2003: report studies on the house mouse), and that male house mice can display mate preference (Christophe and Baudoin, 1998; Drickamer et al., 2003; Gowaty et al., 2003; Smadja et al., 2004; Ganem et al., 2005). Our investigations therefore include both males and females.

A pair of stimuli was composed of a M. m. musculus type stimulus and a $M . m$. domesticus type stimulus. Samples of $10 \mu \mathrm{l}$ urine were deposited on a $1 \mathrm{~cm}^{2}$ blotting paper. The blotting papers containing the two stimuli were taped to the ends of the two secondary branches of the Y maze, which were then sealed.

We controlled for laterality by alternating the right and left position of the stimuli between the tests. After each test, the entire apparatus was thoroughly washed with water and a $20 \%$ alcohol solution. At the beginning of each test, the mouse was placed in the central box. A few minutes of habituation was allowed before opening the door that connected the box to the Y maze. Recording started when the mouse went through the door. In all tests, the mouse entered the two secondary branches repeatedly, which is expected from a wild mouse. We considered that a mouse was on one side of the $\mathrm{Y}$ maze when it crossed the entrance to the secondary branch on that side. Contact with a stimulus was recorded when the individual either sniffed it from a short distance $(\sim 1 \mathrm{~cm})$ or licked it. Each test lasted $10 \mathrm{~min}$. The time spent on each side or in contact with each stimulus was recorded using a Psion Organiser and the Observer software (Noldus Information Technology). A total of 217 mice were tested. Each mouse was tested once.
Data analysis

We analysed variation across the hybrid zone of two variables. The first one is preference $(R)$ and was measured by the log-ratio of time spent in contact with domesticus $\left(T_{m}\right)$ versus musculus $\left(T_{d}\right)$ urinary stimuli $\left(R=\operatorname{Ln}\left(\left(T_{m}+1\right) /\left(T_{d}+1\right)\right)\right)$. The second variable is time of sniff $(T)$. It was defined as the log of the total time spent in contact with either stimulus $\left(T=\operatorname{Ln}\left(T_{m}+T_{d}\right)\right)$ and refers to the total attraction of the two stimuli. The sign of the Ln ratio indicated the direction of a choice. A positive value indicated a preference for the $M . m$. musculus stimulus, whereas a negative value indicated a preference for the $M . m$. domesticus stimulus. Log-transformed variables were used because they were normally distributed.

We used a clinal model to analyse the variation of the two empirical variables $R$ and $T$ across the hybrid zone. These variables were assumed to be drawn from a normal distribution $\mathrm{N}\left(\mu_{x}, \sigma_{x}\right)$, where $\mu_{x}$ and $\sigma_{x}$ are functions of distance $x$ across the hybrid zone. More specifically, $\mu_{x}$ was modelled as $\mu_{\min }+\left(\mu_{\max }-\mu_{\min }\right) p_{x}$, where $\mu_{\min }$ and $\mu_{\max }$ measure the mean in each subspecies and $p_{x}$ is a sigmoid function of distance (with maximum slope $s$ and centre $c$ ). The variance $\sigma_{x}$ was modelled as $p_{x}^{2} \sigma_{1}+2 p_{x}\left(1-p_{x}\right) \sigma_{2}+\left(1-p_{x}\right)^{2} \sigma_{3}$ to account for possible difference among individuals from each subspecies far from the centre $\left(\sigma_{1}\right.$ and $\sigma_{3}$ ) and hybrids closer to the centre $\left(\sigma_{2}\right)$. This model assumes that in each location, the distribution of $R$ (or $T$ ) is unimodal (drawn from a simple normal distribution). We first investigated whether the variation of $R$ and $T$ across the hybrid zone differed between males and females. Because some of the mice were tested in the field (101 individuals) and others in the laboratory 4 months after trapping (70 mice in 1998 and 46 mice in 2000), we also investigated whether the variation of $R$ and $T$ across the hybrid zone differed among these different samples. The sex ratio was similar in the samples tested in the field and in the laboratory. Parameters were estimated by maximum likelihood using the Cfit program (available upon request from TL) and specific hypotheses were tested using likelihood ratio tests.

\section{Results}

\section{Time of sniff $T$}

Duration of sniff does not vary across the hybrid zone for males and females $\left(\mu_{\max }=\mu_{\min }\right.$ is not rejected in each case $P=0.82$ and 0.96 , respectively). Males and females spent the same amount of time sniffing $\left(\mu_{\uparrow}=\mu_{\delta}\right.$ is not rejected $\left.P=0.20\right)$. The only variation that can be detected concerns the variance of $T$ across the hybrid zone for males. It is smaller near the centre of the hybrid zone $\left(\sigma_{1}=\sigma_{2}=\sigma_{3}\right.$ is rejected $P<0.001$, but $\sigma_{1}=\sigma_{3}$ is not rejected $P=0.33$ ). This drop occurs around $5 \mathrm{~km}$ on the musculus side, but this position is not significantly different from the centre of the hybrid zone ( $c=0$ is not rejected $P=0.17$ ). Mean $T$ was not different among samples tested in the field or in the laboratory for males $(P=0.15)$. It was longer for females tested in the laboratory than in the field $(P=0.003)$, which may relate to the females being less tractable, possibly due to stress, when tested in the field. 
Ratio of preference $R$

Musculus males preferred musculus female odours ( $\mu_{\max }=0$ is rejected $P<0.001$ ) whereas domesticus males preferred domesticus female odours $\left(\mu_{\min }=0\right.$ is rejected $P=0.032)$, and preference was stronger on the musculus side (see Table 2). The transition between these two types of preference appears to be abrupt and shifted $\sim 10 \mathrm{~km}$ to the musculus side from the genetic centre $(c=0$ is rejected $P=0.008$; Figure 1 ). At this distance, most individuals $(80 \%)$ have a hybrid index between 0.6 and 0.9 (Table 1, Figure 3). The preference score is very variable among the males $\left(\sigma_{0}=0.77\right)$, but this variance is constant across the zone $\left(\sigma_{1}=\sigma_{2}=\sigma_{3}\right.$ is not rejected $P=0.88)$. In contrast, the female preference score shows no pattern of variation across the hybrid zone $\left(\mu_{\max }=\mu\right.$ min is not rejected $P=0.88$ ) and is in fact not significantly different from $0 \quad(\mu=0$ is not rejected $P=0.77)$. The variance is similar to that found among males, perhaps slightly larger $\left(\sigma_{\varphi}=0.90 ; \sigma_{\varphi}=\sigma_{\delta}\right.$ is not rejected $\left.P=0.09\right)$ and this variance is fairly constant across the hybrid zone

Table 2 Parameter estimates for the cline of male preference score

\begin{tabular}{lccc}
\hline Parameter & Estimate & \multicolumn{2}{c}{ Support limits } \\
\hline$c$ & $10^{\mathrm{a}}$ & 8.2 & 12.3 \\
$w$ & $1^{\mathrm{b}}$ & 0.0 & 26 \\
$\mu_{\min }$ & -0.25 & -0.48 & -0.02 \\
$\mu_{\max }$ & 0.42 & 0.21 & 0.64 \\
$\sigma$ & 0.77 & 0.67 & 0.89 \\
\hline
\end{tabular}

$c$ is the centre of the cline (in $\mathrm{km}$ ) and $w$ is the width (inverse of the maximum slope) of the cline (in $\mathrm{km}$ ). $\mu_{\min }$ and $\mu_{\max }$ are extreme values of mean preference score along the cline and $\sigma$ is the standard deviation of preference score among individuals in a given location.

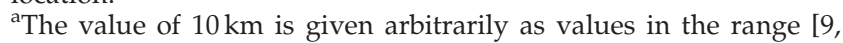
11.6] are equally likely.

${ }^{\mathrm{b}}$ The value of $1 \mathrm{~km}^{-1}$ is given arbitrarily here as the best model is very steep. The likelihood function is maximum but differs by less than 0.01 in the range $[0.0,1.1]$.

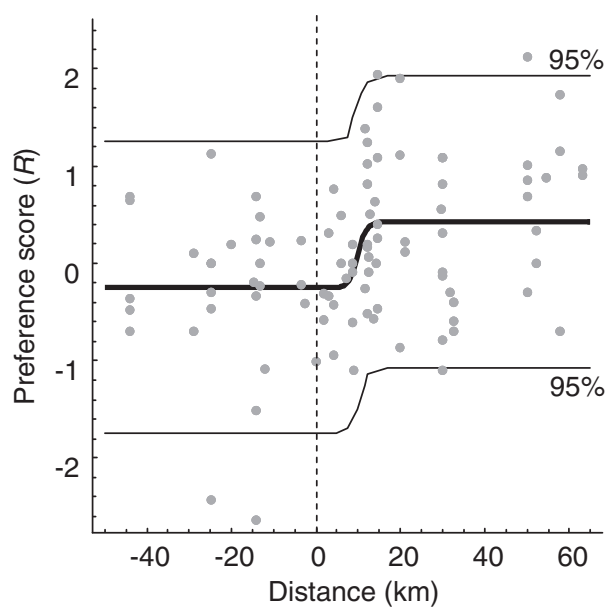

Figure 1 Variation of individual male mice preference ratio across the hybrid zone. The thick line describes the fitted field data, and the lighter lines describe the $95 \%$ confidence interval. On the $x$ axis, $x=0$ corresponds to the centre of the hybrid zone defined by Raufaste et al. (2005); $x>0$ corresponds to the musculus side of the hybrid zone. The distance values for each trapping site involved in the analysis and average preference per sex and site are presented in Table 1.
( $\sigma_{1}=\sigma_{2}=\sigma_{3}$ is not rejected $P=0.08$ ). The pattern of variation of $R$ was similar among samples tested in the field or in the laboratory $(P=0.95$ and $P=0.85$ for males and females, respectively).

\section{Discussion}

Male preference for female urinary stimuli from allopatric populations of the two subspecies is positively assortative in the borders of the hybrid zone, which confirms that the urinary signals of the two subspecies have also diverged in allopatry (Smadja and Ganem, 2008). Moreover, all the allopatric donor populations involved in the present study were sufficiently distant from the hybrid zone that they would not be connected by gene flow. Preference was more marked in musculus males than in domesticus. The asymmetric pattern of preference in the two subspecies was also evident when the odour cues originated from the borders of the hybrid zone (Smadja et al., 2004; Smadja and Ganem, 2005).

Unexpectedly, female preference was not found to be assortative across the hybrid zone. Although sexually receptive $M$. m. musculus females had previously been shown to display assortative preference in populations in the border of the Danish contact zone, and assortative preference for local stimuli was detected in samples of only 10 individuals per population (Christophe and Baudoin, 1998; Smadja and Ganem, 2002; Smadja et al., 2004). We see two possible explanations for the absence of preference in females in this study. The first may be that we did not control for sexual receptivity, which appears to influence preference in house mice in some studies (D'udine and Alleva, 1983; Krackow and Matuschak, 1991; Drickamer, 1992; Rolland et al., 2003), but not others (Laukaitis et al., 1997). If expression of preference depends on hormonal characteristics and hence varies with the oestrus cycle, absence of preference in the females may relate to the heterogeneity of our sample. Alternatively, lack of preference may relate to specific characteristics of female perception of the stimuli involved in this study and/or to a lower divergence of the male stimuli in allopatry. It may also be that female assortative preference in the hybrid zone only concerns local odour cues and relies on recognition by association, which could not occur in our study. These latter hypotheses would involve marked differences in the mate recognition system of the sexes. Further investigations would be needed to evaluate these hypotheses, particularly investigations of the variation of preference of sexually receptive females across the zone, and differences between the sexes in the divergence of allopatric versus contact zone signals and attractiveness.

Variance of preference ratio was relatively high everywhere in the zone, which could be explained by measurement error. However, variation could also be explained by the complexity of factors (environmental, social, ontogenetic and genetics) that may influence this behavioural trait. Furthermore, equal variance of preference ratio across the zone may indicate that if different conditions prevail, their impact on preference does not vary across the zone. Moreover, duration of sniff $(T)$, which might constitute an additional index of the attraction of signals (Bímová et al., 2005), is less variable in the centre as compared to elsewhere in the zone, 
which suggests higher behavioural homogeneity despite genetic variation.

As far as male preference is concerned, the most striking result is that the preference score changes abruptly with a width (inverse of the maximum slope) of $0-3 \mathrm{~km}$ and less than $26 \mathrm{~km}$ at the most. We cannot usefully compare this estimate with the width of the allozyme clines in the same transect because of the excessive uncertainty. We simply note that the width of the allozyme clines in this hybrid zone ranges from 4 to $21 \mathrm{~km}$ with a mean around $9 \mathrm{~km}$ (Raufaste et al., 2005), and hence that the cline width of male preference score is comparable with the narrowest of the allozyme clines. Of particular interest is the shift of the centre of the preference cline $\sim 10 \mathrm{~km}$ towards the musculus side. A similar shift was observed for two supposedly neutral allozyme loci in this transect (Idh and Sod), and Raufaste et al. (2005) evoked the history of contact as one possible explanation for this shift. Nevertheless, the clines for Idh and Sod did not show the sharp step present in the preference cline. Moreover, the shift of its centre could be simply explained by the genetic basis of the preference. The trait certainly appears to be polygenic. Indeed, if preference is determined by a single locus with a dominant domesticus allele $D$, the preference cline would be shifted $\approx 0.17 w_{D} \mathrm{~km}$ (towards the musculus side of the zone) relative to the centre of a cline for $D$ allele that has a width $w_{D}$. It would also be $\approx 1.2$ times steeper than the underlying allelic cline. However, a large shift in the position of the centre $\left(0.17 w_{D}\right)$ appears to be incompatible with a narrow allelic cline. In effect, under the latter hypothesis, to observe a $10 \mathrm{~km}$ shift in the phenotypic cline, the underlying allelic cline would have to be quite wide (around $60 \mathrm{~km}$ ), which is clearly not the observed width of the preference cline or even that of the allozyme clines. Alternatively, let us assume that $n$ biallelic loci contribute to the preference score that we scale in the range $[0,1]$. We note $p=1-q$, the domesticus allele frequency for all loci. Depending on the genotypephenotype map, the preference cline may have a different slope and position from the underlying allelic clines. We will consider four genotype-phenotype mappings. In case (a), each allele acts additively on the character. In case (b), every domesticus allele is dominant at every locus. In case (c), being homozygous for domesticus alleles at any of the $n$ loci causes a domesticus preference (otherwise preference is additive, we will label this case as 'mild epistasis'). In case (d), having a single domesticus allele at any of the $n$ loci causes a domesticus preference ('strong epistasis'). The average preferences can be computed (neglecting linkage disequilibria) to be $p, 1-q^{2}, 1-q^{n}(1+p)^{n-1}$ and $1-q^{2 n}$, respectively. Assuming that allelic clines have a sigmoid shape with a width $w$, it is then straightforward to compute the shift in the position of the phenotypic cline and its width. If one takes the case of a dominant trait determined by one locus, then the cline of the trait is (assuming random mating) $p_{x}^{2}+2 p_{x}\left(1-p_{x}\right) \quad\left(p_{x}\right.$ is the frequency cline of the allele). It is then straightforward to analyse the second derivative of this function to find its maximum slope and position (for instance, assuming that $p_{x}$ has a sigmoid shape). Of course the shift in the position in our example is towards musculus as domesticus alleles are dominant. The result is illustrated in Figure 2. In case (a) (additive), the preference cline is not shifted

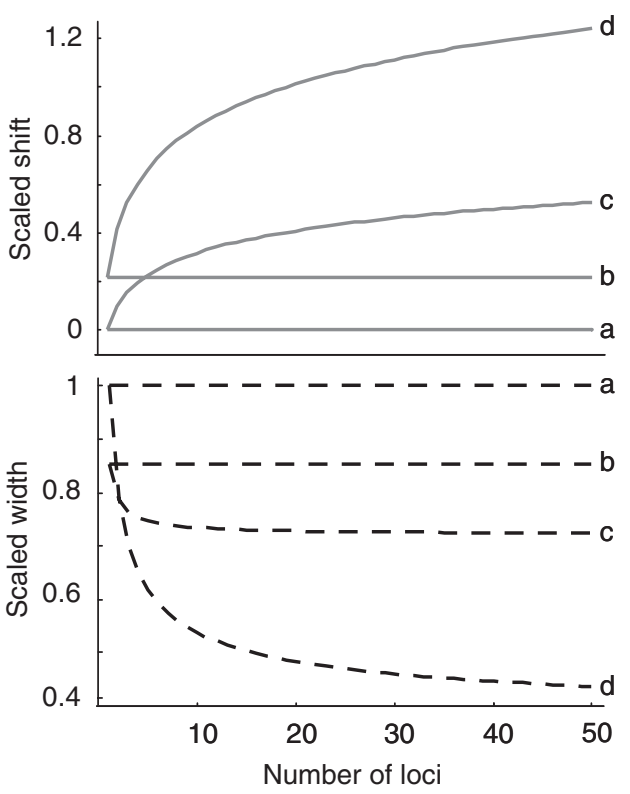

Figure 2 Shift in position and width of the preference cline depending on its genetic basis (a: additive allelic effects; b: dominance; c: mild epistasis; d: strong epistasis; see text for details). The shift in the position is given scaled to the width of the underlying allelic clines (that is, if the underlying allelic clines are $10 \mathrm{~km}$ wide, a scaled shift $=0.5$ means that the centre of the preference cline is shifted $5 \mathrm{~km}$ towards musculus). The width of the preference cline is also expressed as a fraction of the width of the underlying allelic clines (that is, if the underlying allelic clines are $10 \mathrm{~km}$ wide, a scaled width $=0.5$ means that the width of the preference cline is $5 \mathrm{~km}$ ).

and has the same width, no matter the number of underlying loci. In case (b) (dominance), the preference cline is shifted $\sim 0.2 w \mathrm{~km}$ and is narrower $(\sim 0.84 w)$, no matter the number of underlying loci. In cases (c) and (d) (mild and strong epistasis), the number of loci matters. In both cases, the shift in the position increases and the preference cline becomes narrower with an increasing number of loci and the effect is more pronounced for strong epistasis. The narrow and strongly shifted preference cline that we observe is therefore consistent with case (c) or (d) and excludes cases (a) and (b). With these different scenarios, we would expect higher genetic variance for preference within than at the edge of the hybrid zone. We do not detect this trend, which may be simply due to the large environmental and error variance, or the influence of epigenetic factors not included in our model. Alternatively, higher genetic variance within the hybrid zone may result in a relatively homogeneous phenotype due to either hybrid dysfunction or increased efficiency in recognition. Furthermore, Christophe and Baudoin (1998) have assessed preference (although not with the same stimuli as those used here) of F1 individuals obtained from crosses between mice at the borders of the Danish hybrid zone. They did not detect a domesticus preference: in their case, F1 preference is non-directional or possibly biased towards musculus. This outcome would be expected in case (c) (because F1 are heterozygous at all loci) but not in case (d). This suggests that preference may be determined by several loci with the effect of loci that are homozygous for the domesticus allele dominating the effect of alleles at other 
600

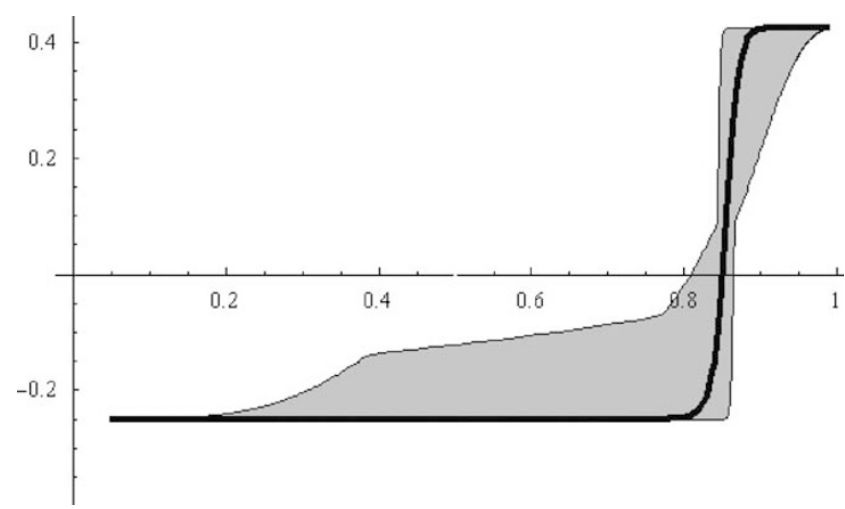

Figure 3 The best-fitted cline of the phenotype-genotype relationship for preference among hybrid genotypes that could account for the pattern of preference of male mice trapped along a transect crossing the Danish hybrid zone. The $x$ axis represents the average frequencies of M. m. musculus alleles (HI). The solid line describes the fitted field data and the grey surface indicates the confidence area reconstructed conservatively by taking into account the uncertainty in the estimates of both the hybrid index cline (from Raufaste et al., 2005) and the preference cline (see Table 2).

loci (case (c)). With such a genetic basis, the preference of recombined hybrids in the wild is indeed expected to strongly differ from that of F1, which are heterozygous at all loci, and preference for domesticus to be largely shifted towards the musculus side of the zone. To further confirm our hypothesis would require measuring preference in F1 (that can be obtained in laboratory conditions) for stimuli similar to those used in this study.

In this study, we measured preference, and our discussion relates to this behavioural trait. Nevertheless, if species preference in the house mouse is based on a simple self-referencing mechanism (Todrank et al., 2005), and preference is assortative, patterns of preference across the hybrid zone might also indicate that most hybrids are characterized by a domesticus-type signal and the shape of the preference cline would also reflect variation of signal characteristics.

Whether the preference or the allozyme clines are considered, when asymmetry is observed, it is always in the direction of more introgression into the musculus side of the hybrid zone. Similar results were reported in several studies involving different locations along the hybrid zone (for a review see Raufaste et al., 2005), suggesting that the pattern is not explained by local conditions. Progression of M. m. domesticus into M. m. musculus territory is consistent with behavioural observations of dominance of M. m. domesticus mice over M. m. musculus (Thuesen, 1977; Van Zegeren and Van Oortmerssen, 1981). Consequently, historical or contemporary progression of $M$. $m$. domesticus into M. m. musculus territory may best describe the situation in Denmark. Moreover, if reinforcement took place in the Danish hybrid zone (Smadja and Ganem, 2005), a more marked divergence in $M$. m. musculus could be the consequence of asymmetry in migration success between the two subspecies due to behavioural dominance of $M . m$. domesticus type mice even when in the territory of M. m. musculus (see discussion in Smadja et al., 2004).

The genetics of mate choice is critical to the likelihood of speciation models. However, the analysis of the genetics of mate choice is a complex task, and the scarce information gathered on the subject mainly concerns the fruitfly and the moth (Ritchie and Philips, 1998; Coyne and Orr, 2004; Chenoweth and Blows, 2006). Moreover, divergence in mate choice was more often found to involve changes at several loci (Coyne and Orr, 2004) than at a single one (Ortiz-Barrientos and Noor, 2005). Our study provides the first indirect information on a possible genetic determinism of preference in a mammal, and our results suggest the involvement of a polygenic autosomal system with dominance and epistasis.

\section{Acknowledgements}

We thank the farmers of Jutland (Denmark), who let us trap mice on their property, and JT Nielsen, who collected the Odder M. m. musculus mice. We are grateful to R Osterballe and the Givskud zoo, and the 1998 field team with whom the trapping was done (Laboratory Genome Population Interaction Adaptation, UMR 5171); Gilbert Pistre for the design and building of the behavioural apparatus; and $\mathrm{M}$ Perriat-Sanguinet for maintaining the mice in Montpellier. We thank $\mathrm{J}$ Britton-Davidian and J Catalan for their generous help in collecting some of the urine samples and for their constant support, C Smadja for sharing mice collected in 2000 and P Boursot, J Britton-Davidian, B Dod and C Smadja as well as several anonymous referees for comments on different versions of the manuscript. This is contribution no. ISEM 2008-021.

\section{References}

Barton KE, Hewitt G (1985). Analysis of hybrid zones. Ann Rev Ecol Syst 16: 113-148.

Bímová B, Karn RC, Píalek J (2005). The role of salivary androgen-binding protein in reproductive isolation between two subspecies of house mouse: Mus musculus musculus and Mus musculus domesticus. Biol J Linn Soc 84: 349-361.

Boursot P, Auffray J-C, Britton-Davidian J, Bonhomme F (1993). The evolution of house mice. Ann Rev Ecol Sys 24: 119-152.

Britton-Davidian J, Fel-Clair F, Lopez J, Alibert P, Boursot P (2005). Postzygotic isolation between the two European subspecies of the house mouse: estimates from fertility patterns in wild and laboratory-bred hybrids. Biol J Linn Soc 84: 379-393.

Bronson CL, Grubb TC, Sattler GD, Braun MJ (2003). Mate preference: a possible causal mechanism for a moving hybrid zone. Anim Behav 65: 489-500.

Chenoweth SF, Blows MW (2006). Dissecting the complex genetic basis of mate choice. NatRev Genet 7: 681-692.

Christophe N, Baudoin C (1998). Olfactory preferences in two sub-species of mice Mus musculus musculus and Mus musculus domesticus and their hybrids. Anim Behav 56: 365-369.

Coyne JA, Orr HA (2004). Speciation. Sinauer Associates Inc.: Sunderland.

D'udine B, Alleva E (1983). Early experience and sexual preferences in rodents. In: Bateson P (ed). Mate Choice. Cambridge University Press: Cambridge. pp 311-327.

Dewsbury DA (1982). Ejaculate cost and male choice. Am Nat 119: 601-610.

Dod B, Smadja C, Karn RC, Boursot P (2005). Testing for selection on the androgen-binding protein in the Danish mouse hybrid zone. Biol J Linn Soc 84: 447-459.

Drickamer LC (1992). Oestrous female house mice discriminate dominant from subordinate males and sons of dominant 
from sons of subordinate males by odour cues. Anim Behav 43: 868-870.

Drickamer LC, Gowaty PA, Wagner DM (2003). Free mutual mate preferences in house mice affect reproductive success and offspring performance. Anim Behav 65: 105-114.

Ganem G, Ginane C, Ostrowski M-F, Orth A (2005). Assessment of mate preference in the house mouse with reference to investigations on assortative mating. Biol J Linn Soc 84: 461-471.

Gowaty PA, Drickamer LC, Schmid-Holmes S (2003). Male house mice produce fewer offspring with lower viability and poorer performance when mated with females they do not prefer. Anim Behav 65: 95-103.

Hatfield T (1997). Genetic divergence in adaptive characters between sympatric species of stickleback. Am Nat 149: 1009-1029.

Hauber ME, Sherman PW (2001). Self-referent phenotype matching: theoretical considerations and empirical evidence. Trends Neurosci 24: 609-616.

Heth G, Todrank J, Busquet N, Baudoin C (2003). Genetic relatedness assessment through individual odour similarities in mice. Biol J Linn Soc 78: 595-603.

Hurst JL (1990a). Urine marking in populations of wild house mice Mus domesticus Rutty. I. Communication between males. Anim Behav 40: 209-222.

Hurst JL (1990b). Urine marking in populations of wild house mice Mus domesticus Rutty. II. Communication between females. Anim Behav 40: 223-232.

Krackow S, Matuschak B (1991). Mate choice for non-siblings in wild house mice: evidence from a choice test and a reproductive test. Ethology 88: 99-108.

Lambert DM, Spencer HG (1995). Speciation and The Recognition Concept. Theory and Application. The Johns Hopkins University Press: London.

Laukaitis CM, Crister ES, Karn RC (1997). Salivary androgenbinding protein (ABP) mediates sexual isolation in Mus musculus. Evolution 51: 2000-2005.

Littlejohn MJ (1993). Homogamy and speciation: a reappraisal. In: Futuyama D, Antonovics J (eds). Oxford Surveys in Evolutionary Biology. Oxford University Press: Oxford. pp 135-166.

Macholán M, Munclinger P, Šugerková M, Dufková P, Bímová B, BoSYMBOL $88 \backslash \backslash f$ "MacAccents" \s 12iková E et al. (2007). Genetic analysis of autosomal and X-linked markers across a mouse hybrid zone. Evolution 61: 746-771.

Moulia C, Aussel JP, Bonhomme F, Boursot P, Nielsen JT, Renaud F (1991). Wormy mice in a hybrid zone: a genetic control of susceptibility to parasite infection. J Evol Biol 4: 679-687.

Orth A, Lyapunova E, Kandaurov A, Boissinot S, Boursot P, Vorontsov N et al. (1996). L'espèce polytypique Mus musculus en Transcaucasie. CR Acad Sci Paris 319: 435-441.

Ortiz-Barrientos D, Noor MAF (2005). Evidence for a one-allele assortative mating locus. Science 310: 1467.

Paterson HEH (1985). The recognition concept of species. In: Vrba ES (ed). Species and Speciation. Transvaal Museum: Pretoria. pp 21-29.

Payseur BA, Krenz JG, Nachman MW (2004). Differential patterns of introgression across the $X$ chromosome in a hybrid zone between two species of house mice. Evolution 58: 2064-2078.
Penn D, Potts WK (1998). Untrained mice discriminate MHC-determined odors. Physiol Behav 63: 235-243.

Raufaste N, Orth A, Belkhir K, Senet D, Smadja C, Baird SJE et al. (2005). Inference of selection and migration in the danish house mouse hybrid zone. Biol J Linn Soc 84: 593-616.

Rhymer JM, Simberloff D (1996). Extinction by hybridization and introgression. Ann Rev Ecol Syst 27: 83-109.

Ritchie MG, Philips DF (1998). The genetics of sexual isolation. In: Howard DJ, Berlocher SH (eds). Endless Forms: Species and Speciation. Oxford University Press: New York, Oxford, pp 291-308.

Rolland C, MacDonald DW, De Fraipont M, Berdoy M (2003). Free female choice in house mice: leaving best for last. Behaviour 140: 1371-1388.

Rosenfield JA, Kodric-Brown A (2003). Sexual selection promotes hybridization between Pecos pupfish, Cyprinodon pecosensis and sheepshead minnow, C variegatus. J Evol Biol 16: 595-606.

Ryan MJ, Rand AS (1993). Species recognition and sexual selection as a unitary problem in animal communication. Evolution 47: 647-657.

Smadja C, Catalan J, Ganem G (2004). Strong premating divergence in a unimodal hybrid zone between two subspecies of the house mouse. J Evol Biol 17: 165-176.

Smadja C, Ganem G (2002). Subspecies recognition in the house mouse: a study of two populations from the border of a hybrid zone. Behav Ecol 13: 312-320.

Smadja C, Ganem G (2005). Asymmetrical reproductive character displacement in the house mouse. J Evol Biol 18: 1485-1493.

Smadja C, Ganem G (2008). Divergence of odorant signals within and between the two European subspecies of the house mouse. Behav Ecol 19: 223-230.

Tang-Martinez Z (2001). The mechanisms of kin discrimination and the evolution of kin recognition in vertebrates: a critical re-evaluation. Behav Process 53: 21-40.

Thuesen P (1977). A comparison of the agonistic behaviour of the Mus musculus L. and Mus musculus domesticus Rutty (Mammalia and Rodentia). Vidensk Dan Naturhist Foren 140: 117-128.

Todrank J, Busquet N, Baudoin C, Heth G (2005). Preferences of newborn mice for odours indicating closer genetic relatedness: is experience necessary? Proc Roy Soc B 272: 2083-2088.

Van Zegeren K (1980). Variation in aggressiveness and the regulation of numbers in house mouse populations. Netherlands J Zool 30: 635-770.

Van Zegeren K, Van Oortmerssen GA (1981). Frontier disputes between the West- and East-European house mouse in Schleswig-Holstein, West Germany. Z Säugetierkunde 46: 363-369.

Vedenina VY, Helversen OV (2003). Complex courtship in a bimodal grasshopper hybrid zone. Behav Ecol Sociobiol 54: 44-54.

Wagner WE (1998). Measuring female mating preferences. Anim Behav 55: 1029-1042.

Wells MM, Henry CS (1998). Songs, reproductive isolation, and speciation in cryptic species of insects: a case study using green lacewings. In: Howard DJ, Berlocher SH (eds). Endless Forms: Species and Speciation. Oxford University Press: New York, pp 217-233. 